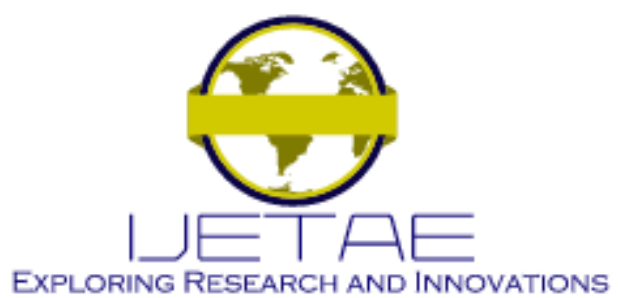

International Journal of Emerging Technology and Advanced Engineering

Website: www.ijetae.com (E-ISSN 2250-2459, Scopus Indexed, ISO 9001:2008 Certified Journal, Volume 12, Issue 01, January 2022)

\title{
Thermal Impact of Lightning Current Injection into A Floor Housing High-Voltage Substations
}

\author{
MWANAMPUTU MBWANZO Clément ${ }^{1}$, Aristide MANKITI FATI ${ }^{2}$, LIDINGA MOBONDA Flory ${ }^{1}$, \\ NSONGO Timothée ${ }^{4}$, PASI BENGI MASATA André ${ }^{4}$, GOMBA Rodolphe ${ }^{2}$ \\ ${ }^{1}$ Laboratory of Electronic Engineering, of The Higher Institute of Applied Technique. DC Kinshasa. \\ ${ }^{2}$ Laboratory of Electrical and Electronic Engineering, Marien Ngouabi University at The National Superior Polytechnic School, \\ Congo Brazzaville. \\ ${ }^{3}$ Laboratory of Electronic and Electronic Engineering, of The Higher Institute of Applied Technique. DRC-BOMA \\ ${ }^{4}$ Laboratory of Physics, Marien Ngouabi University at The Science And Technology Facility, Congo Brazzaville
}

\begin{abstract}
In this paper the ionization problem of the ground, during the injection of lightning current through the earth of electrical installations is presented; this soil degradation has negative consequences on the performance of the earth electrodes through its transient impedance.

To resolve this problem, we analyzed the measured samples of the earth resistance of the Lingwala / Kinshasa HV substation, where the soil is sandy-clay; the model of the dynamics of soil heating for a temperature variation simulated in Matlab gave us satisfactory results characterized by a decreasing exponential of the resistivity of the soil which gives the image of the pre-ionization which means an impedance low-value earth electrode transient which reflects its good performance.

These encouraging results are safety indicators for electrical installations; they are aimed particularly at designers of industrial installations, operators of $\mathrm{HV}$ substations in electrical networks, and managers of buildings open to the public such as banks, hospitals, and large spaces.
\end{abstract}

Keywords-- Thermal impact; injection; Lightning current; Ground; Job; High tension

\section{INTRODUCTION}

The analysis of lightning climatology data in the Congo Basin provided by the WWLLN (World Wide Lightning Location Network) in the period from 2005 to 2013, reveals that Central Africa and more particularly, the Democratic Republic of the Congo beats the world record for thunderstorm activity that is the cause of lightning formation [1-2].

In the context of securing the equipment of the $\mathrm{HV}$ substation and people located in its close environment, and low, medium, and high voltage electrical installation must install the earth socket, a low impedance path to facilitate the flow of lightning current on the ground.
Suddenly, this flow gives rise to soil degradation phenomena as a result of its electrical and thermal ionization, thus leading to a reduction in the impedance of the earth electrode.

Considering that the quality of service, the stability, and the security of the electrical network depend on the knowledge and the control of its transient regime, this publication seeks to show, from the thermal balance of the passage of the current in the ground, the evolution of the transient impedance and the distribution of the potential difference around the earth connection as a function of the thermal effects induced by the current flow to the ground via the earth connection of the HV substation.

The experimental method of taking samples of the resistances of the earth electrodes measured at a depth recommended by the standards, the intensities of the lightning current recorded at the Lingwala substation, and the Matlab digital simulation tool made it possible to obtain the desired results.

\section{Thermal EFFECTS During The INJECTION OF LIGHTNING CURRENT INTO THE GROUND}

Regarding the thermal effects occurring in the soil during the injection of the lightning current, it is therefore essential to note that an increase in the temperature of the soil up to $100^{\circ} \mathrm{C}$ leads to evaporation of water from the soil and therefore an increase in its resistivity. When the temperature falls below $0^{\circ} \mathrm{C}$ as in the case of cold regions, the conductivity of the electrolyte decreases, and thus a rapid increase in resistivity occurs.

In addition to the temperature of the soil, other factors contribute to this formation of electrolytes including porosity; the percentage of water contained in the soil; the percentage of soluble salts, acids, and bases. 


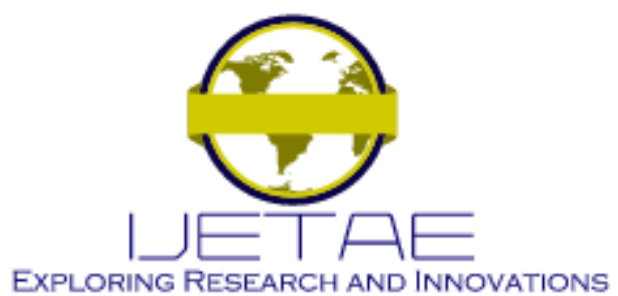

International Journal of Emerging Technology and Advanced Engineering

Website: www.ijetae.com (E-ISSN 2250-2459, Scopus Indexed, ISO 9001:2008 Certified Journal, Volume 12, Issue 01, January 2022)

The electric current that circulates in the ground produces a transfer of energy by the Joule effect in the form of heat; which leads to an increase in the temperature of the medium. The power dissipated in the ground per unit volume becomes [2]:

$$
P=E J=\rho J^{2}=\frac{E^{2}}{\rho}
$$

Where E: the electric field in the ground in $\mathrm{V} / \mathrm{m}$

$\mathrm{J}$ : The density of the current in $\mathrm{A} / ; \mathrm{m}^{2}$

$\rho$ : The resistivity of the soil in $\Omega \mathrm{m}$; for the city of Kinshasa in the Democratic Republic of the Congo, the soil is clay-sandy with, $\rho=50$ to $500 \Omega \mathrm{m}$ according to the table above [2]

Among the specific characteristics of a soil type that particularly influence the calculation of groundings, we retain:

The specific heat $\gamma_{r}$ expressed in $\mathrm{J} /\left(\mathrm{m} 3{ }^{\circ} \mathrm{C}\right)$ of the soil, is the amount of heat needed to increase by $1{ }^{\circ} \mathrm{C}$ a volume of $1 \mathrm{~m}^{3}$ of soil; it depends on the type of soil and increases with its relative humidity[2,3].

For clay-sandy soil $0.42 \mathrm{~W} / \mathrm{m}$. ${ }^{\circ} \mathrm{C}$ for dry soil and

$Y=1.95 \mathrm{~W} / \mathrm{m}$. ${ }^{\circ} \mathrm{C}$ for soil saturated with $100 \%$ water

\section{UNDERFLOOR HEATING DYNAMICS}

Knowing that heat transfer in the soil occurs by conduction and by Convection, the heat released by the passage of electric current in the ground per unit volume is according to Joules' law [4]:

$$
\frac{q}{v}=j^{2} p t
$$

Where q: is the thermal energy released in joules;

$\mathrm{v}$ : the volume of the soil in $\mathrm{m}^{3}$

$\mathrm{j}$ : is the density of the current in $; A / \mathrm{m}^{2}$

$\rho:$ is the resistivity of the soil in $\Omega \mathrm{m}$;

$\mathrm{t}$ : flow time in $\mathrm{s}$.

The energy released $q$ can reach great values if the resistivity of the soil or the density of the current is high. The heat released is partly stored in the soil and causes an increase in the temperature of the environment while the unstored heat diffuses in the soil to places where the temperature is lower.
Thus. The amount of heat stored depends on the specific heat of the soil and the heat conducted depends on the thermal conductivity.

To determine and illustrate the thermal process in the soil, we analyze the case of a spherical ground intake sunk very deep and surrounded by a soil of resistivity $\rho$ and which disperses a current I according to the figure below.

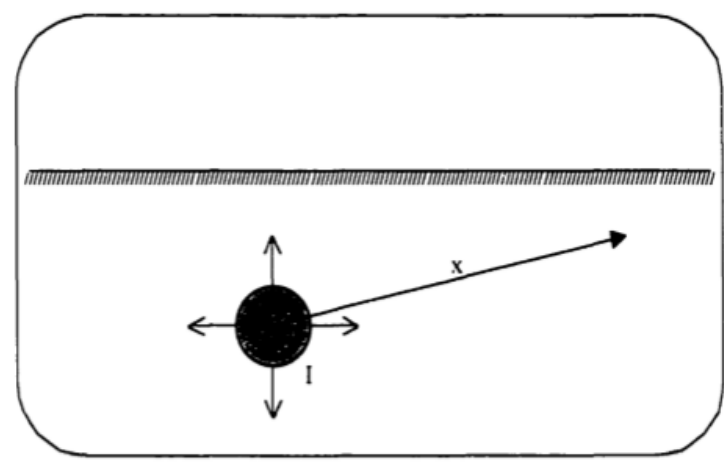

Figure 1: Spherical grounding in the ground.

To determine the density of the current in the ground at a distance $\mathrm{x}$ from the center of the spherical ground socket [5], we will start from the equation:

$$
\iint_{s} n j d S
$$

Knowing that $\mathrm{S}$ and $\mathrm{x}$ are respectively the surfaces and the radius of the sphere, the density of the current injected into the ground becomes:

$$
I=\frac{I}{4 \pi x^{2}}
$$

The heat released is the sum of the stored heat and the heat conducted.

The differential equation of the heat balance is given according to the equation below:

$$
j^{2} \rho d t=\gamma d \theta-\frac{A}{x} \frac{d^{2}(x \theta)}{d x^{2}} d t
$$

Where $\theta$ : soil temperature in $\theta^{\circ} \mathrm{C}$

$$
\begin{aligned}
& \wedge: \text { the thermal conductivity of the soil } \\
& Y: \text { the specific heat of the soil in } \mathrm{J} /\left(\mathrm{m}^{3}{ }^{\circ} \mathrm{C}\right)
\end{aligned}
$$

For a spherical grounding, this equation becomes:

$$
\rho\left(\frac{I}{4 \pi x^{2}}\right)^{2}=\gamma \frac{d \theta}{d t}-\frac{A}{x} \frac{d^{2}}{d x^{2}}
$$




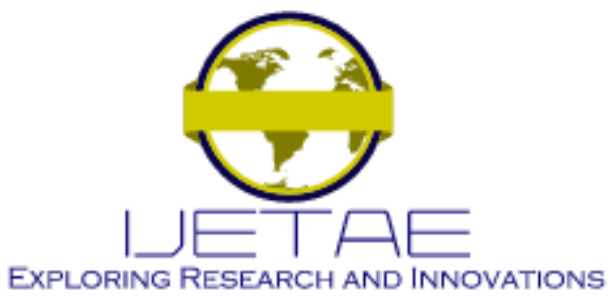

International Journal of Emerging Technology and Advanced Engineering

Website: www.ijetae.com (E-ISSN 2250-2459, Scopus Indexed, ISO 9001:2008 Certified Journal, Volume 12, Issue 01, January 2022)

The above equation has no general solution when the density $\mathbf{J}$ of the current varies with the distance $\mathrm{x}$ from the center of the sphere. However, this equation is used in the calculation of two practical cases:

\section{1. circulation of a current to the ground for a long time.}

The hypothesis of a constant temperature can be posed because the release of heat is long-lasting; Where from $\frac{d \theta}{d t}=0$

Re-evaluating equation (5) we obtain:

$$
x^{d^{2}(x \theta)} \frac{p}{d x^{2}}+\frac{d^{2}}{x^{3}} \frac{(4 \pi)^{2}}{(4)}=0
$$

The solution of this equation is of the form:

$$
\theta=\frac{p}{a x}\left(\frac{I}{4 \pi}\right)^{2}\left(\frac{2 x-r}{2 r x}\right)
$$

Where $\mathrm{r}$ : is the radius of the sphere

The maximum temperature of the soil is on the surface of the earth; it is determined by posing $\mathrm{r}=\mathrm{x}$ and the solution of the equation becomes:

$$
\theta_{r}=\frac{p}{2 n}\left(\frac{I}{2 \pi r}\right)^{2}
$$

This temperature depends on the characteristic properties of the soil $\wedge$ and $\rho$, the square of the dissipated current, and the geometry of the ground intake.

Below are the tables of the different values of $\rho$ and $\wedge$ for different types of soil housing the ground sockets of the HT Substations.
Table1:

Different values of $\rho$ and $\wedge$ for different types of soil housing the ground sockets of the HT substations [10]

\begin{tabular}{|l|l|}
\hline Nature of the land & Resistivity $\Omega m$ \\
\hline Marshy land & 1 to 30 \\
\hline Lemon & 20 to 100 \\
\hline Humus & 10 to 150 \\
\hline Jurassic Marls & 30 to 40 \\
\hline Clay sand & 50 to 500 \\
\hline Sand silicithem & 200 to 3000 \\
\hline Bare stony floor & 1500 to 3000 \\
\hline $\begin{array}{l}\text { Stony floor covered with } \\
\text { Lawn }\end{array}$ & 300 to 500 \\
\hline Soft limestones & 100 to 300 \\
\hline Cracked limestone & 500 to 1000 \\
\hline Micaschists & 800 \\
\hline Granite and sandstone in alteration & 1500 to 10000 \\
\hline $\begin{array}{l}\text { Highly altered granite and } \\
\text { sandstone }\end{array}$ & 100 to 600 \\
\hline
\end{tabular}

\begin{tabular}{|l|c|c|}
\hline \multirow{2}{*}{ Soil type } & \multicolumn{2}{|c|}{ Thermal conductivity (W/m. $\left.{ }^{\circ} \mathbf{C}\right)$} \\
\cline { 2 - 3 } & Dry soil & $\begin{array}{c}\text { Soil saturated with 100\% } \\
\text { water }\end{array}$ \\
\hline Gravel with sand and silt & 0.55 & 2.55 \\
\hline Sand with silt and clay & 0.43 & 1.90 \\
\hline Clay with sand & 0.42 & 1.95 \\
\hline Marl with sand & 0.37 & 0.88 \\
\hline Marne with very fine & 0.33 & 2.30 \\
sand & & 1.65 \\
\hline Sand & 0.27 & 1.13 \\
\hline Black Earth & 0.18 & 0.62 \\
\hline Volcanic land & 0.13 & 0.025 \\
\hline Air & \multicolumn{2}{|c|}{0.23} \\
Beaten snow & \multicolumn{2}{|c|}{0.606} \\
Water & \multicolumn{2}{|c|}{2.22} \\
Ice & & \\
\hline
\end{tabular}




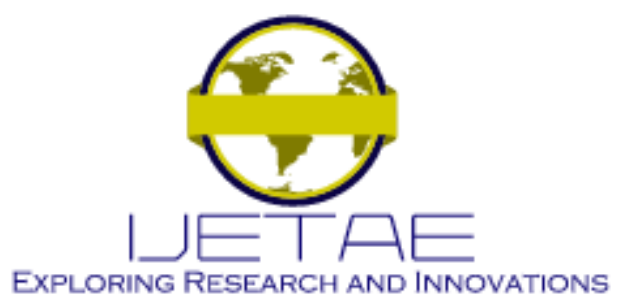

International Journal of Emerging Technology and Advanced Engineering

Website: www.ijetae.com (E-ISSN 2250-2459, Scopus Indexed, ISO 9001:2008 Certified Journal, Volume 12, Issue 01, January 2022)

To avoid drying the temperature of the ground in contact with the ground socket, this temperature must not exceed $100^{\circ} \mathrm{C}$.

The permissible temperature increase is given by: $\Delta \theta$

$$
\Delta \theta=\theta_{m}-\theta_{i} \leq 100
$$

$(10)^{\circ} \mathrm{C}$

$\theta_{\mathrm{i}}:$ is the initial temperature

The figure below illustrates the variation in ground temperature as a function of the distance $\mathrm{x}$ measured from the center of the ground intake.

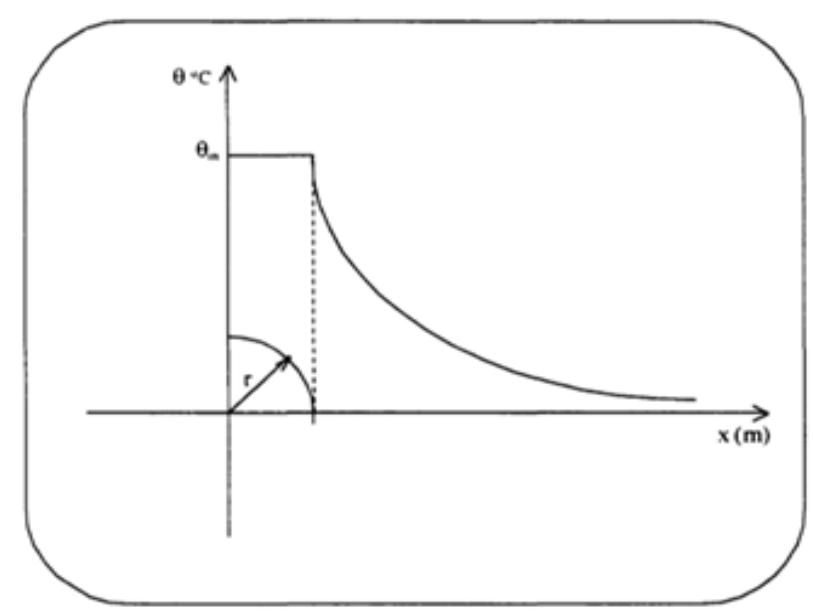

Figure 2: Temperature distribution around a spherical ground intake buried deep in the ground.

The equation below is used to determine the permissible current dissipated by the spherical ground socket [6]

$$
I=4 \pi r \sqrt{\frac{2 \pi \Delta \theta}{\rho}}
$$

The earth resistance of a hemispherical shape taking being related to its radius, we have:

$$
R=\frac{p}{4 \pi y}
$$

The permissible current dissipated becomes: $I=\frac{1}{R} \sqrt{2 \rho \wedge \Delta \theta}$

From equation (13), we can draw the resistivity of the soil to give an equation of resistivity as a function of the ground temperature when injecting the lightning current to the ground.

$$
\rho=\frac{R^{2} T^{2}}{2 n \Delta \theta}
$$

From equation (14), it can therefore be said that the variation in the resistivity of the soil is a function of the square of the injected current and the resistance of the grounding, the climatic conditions but also the thermal effects induced at the time of the injection of this current. The permissible voltage drop on the ground outlet during a long heating period is given by the equation below:

$$
V=R I=\sqrt{2 \rho \wedge \Delta \theta}
$$

The equations (14) and (15) were obtained to allow the simulation of the thermal impact of the lightning current injected into the ground on the resistivity and the distribution of the potential around the ground socket of the High Voltage substations.

\subsection{Lightning amplitude and earth resistance measured at the Lingwala HV substation in Kinshasa/DRC}

It was noticed in Kinshasa/DRC, lightning surges last from 70 seconds to 450 seconds with values beyond 4 Un for lightning current peaks, on the curves of figure 3, correspond exactly amplitudes ranging from 100KA to 200KA [7] [8].

Starting from these two extreme values, we take an average of $60 \mathrm{kA}$ to show the thermal impact of the lightning current on the resistivity of the soil.

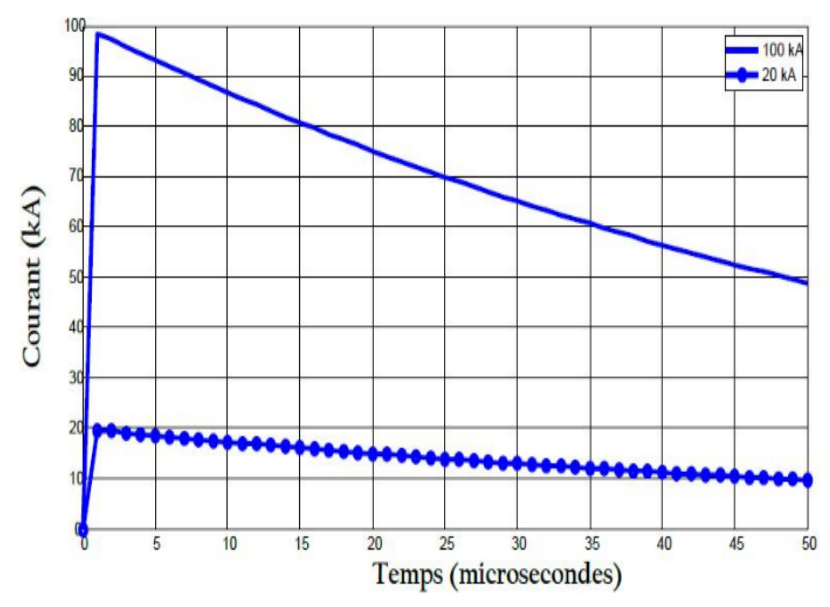

Figure 3: Furnace current curve recorded at the Lingwala HV station. 


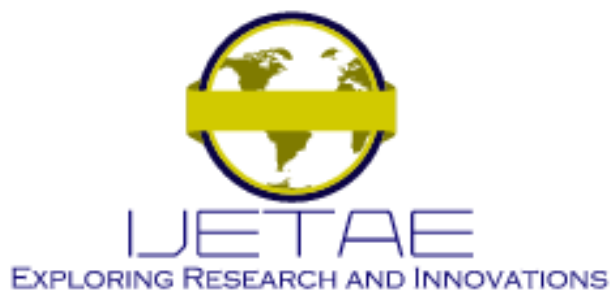

International Journal of Emerging Technology and Advanced Engineering

Website: www.ijetae.com (E-ISSN 2250-2459, Scopus Indexed, ISO 9001:2008 Certified Journal, Volume 12, Issue 01, January 2022)

To experiment with the impact of temperature on the electrical characteristics of the soil i.e. its resistivity and the distribution of the potential (step voltage) around the ground intake by the expressions (14) and (15) for the case of the Lingwala HT substation in Kinshasa/DRC, we take into account the values of earth resistance measured at the station during March and April of the year 2020, the heavily rainy months of the year for the tropical climate.

\section{Measuring apparatus used}

\section{-METRIX MX 435 D}

A multifunction installation tester with the following features:

-max test voltage: $500 \mathrm{~V}$,

-max test intensity: $1 \mathrm{~mA}$,

-max ground resistance range: $2000 \mathrm{ohms}(20 ; 2000 \mathrm{ohms})$

-with accessories (measuring cords and 2 earth stakes)

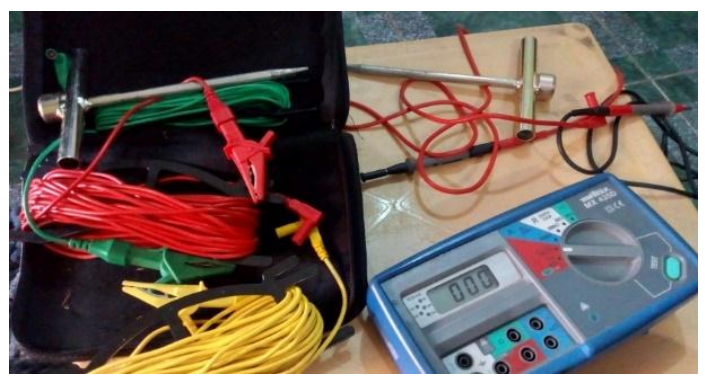

Figure 4: Equipment used to measure the ground resistance of the Lingwala/Kinshasa HV substation

The table below gives the ground resistance measurements at the Lingwala HT substation for March and April 2020
Table 3:

Resistance measurements

\begin{tabular}{|c|c|c|c|c|}
\hline Date & $\begin{array}{l}\text { Characteristics } \\
\text { Equipment }\end{array}$ & $\begin{array}{l}\text { Caliber: } \\
20 \Omega\end{array}$ & $\begin{array}{l}\text { Measured } \\
\text { value in } \Omega\end{array}$ & $\begin{array}{l}\text { Depth } \\
\text { in } m\end{array}$ \\
\hline $02 / 03 / 2020$ & \multirow{6}{*}{$\begin{array}{l}\text { METRIX } \\
\text { MX } 435 \text { D }\end{array}$} & \multirow{8}{*}{$20 \Omega$} & 11.2 & 0.8 \\
\hline $09 / 03 / 2020$ & & & 11.5 & 0.8 \\
\hline $16 / 03 / 2020$ & & & 10.7 & 0.8 \\
\hline $23 / 03 / 2020$ & & & 10.6 & 0.8 \\
\hline $05 / 04 / 2020$ & & & 9.3 & 0.8 \\
\hline $12 / 04 / 2020$ & & & 9.7 & 0.8 \\
\hline $19 / 04 / 2020$ & \multirow{2}{*}{ Rmax: $2000 \Omega$} & & 10.7 & 0.8 \\
\hline $26 / 04 / 2020$ & & & 11.3 & 0.8 \\
\hline
\end{tabular}

After observing different measures of resistance, small variations emerge whose average for the month of mars and April 2020 is $11 \Omega$ :

Considering that the temperature of the ground increases according to the depth of penetration of the earth electrodes, sheltered from seasonal variations and a few meters from the ground, the ground temperature is stable or an average of 14 in the plains at low altitude [8] [9]. ${ }^{\circ} \mathrm{C}$

In the context of our investigations, considering that the law of variation of the ground temperature is complex, two hypotheses are possible:

- The variation in ground temperature, in the range of 14 to $100{ }^{\circ} \mathrm{C}$, is due solely to the amplitude of the lightning current; or an average of $60 \mathrm{kA}$ according to the curve in Figure 3.

- The current injected by lightning can vary from 100 $\mathrm{kA}$ to $20 \mathrm{kA}$ resulting in a variation in the ground temperature in the same range.

The tables below give the values of the resistivity and the potential of the grounding of the Lingwala HT substation for the two possible cases mentioned above. 


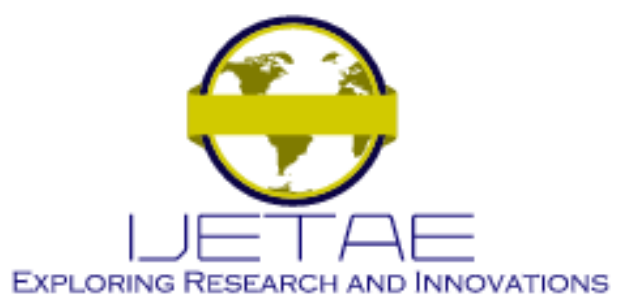

International Journal of Emerging Technology and Advanced Engineering

Website: www.ijetae.com (E-ISSN 2250-2459, Scopus Indexed, ISO 9001:2008 Certified Journal, Volume 12, Issue 01, January 2022)

Table 4:

The resistivity and the potential of the grounding of the Lingwala HT substation

\begin{tabular}{|c|c|c|c|c|c|c|c|}
\hline & I & $\mathrm{N}_{\mathrm{H} 2 \mathrm{O}}$ & $\mathrm{R}$ & $\Delta \theta$ & $\rho$ & In & Observation \\
\hline 1 & \multirow{7}{*}{60} & \multirow{7}{*}{19.5} & \multirow{7}{*}{11} & 14 & 797.8 & 659.99 & \multirow{7}{*}{$\cong 660 \mathrm{~V}$} \\
\hline 2 & & & & 28 & 398.9 & 659.99 & \\
\hline 3 & & & & 42 & 265.9 & 659.95 & \\
\hline 4 & & & & 56 & 199.4 & 659.91 & \\
\hline 5 & & & & 70 & 159.5 & 659.87 & \\
\hline 6 & & & & 84 & 132.9 & 659.83 & \\
\hline 7 & & & & 98 & 113.7 & 659.2 & \\
\hline
\end{tabular}

Table 5:

The resistivity and the potential of the grounding of the Lingwala HT substation

\begin{tabular}{|c|c|c|c|c|c|c|c|}
\hline & I & $\Lambda_{H 2 O}$ & $\mathrm{R}$ & $\Delta \theta$ & $\rho$ & In & Observation \\
\hline 1 & 25 & \multirow{7}{*}{19.5} & \multirow{7}{*}{11} & 14 & 138.5 & 274.9 & 275 \\
\hline 2 & 35 & & & 28 & 135.7 & 384.9 & 385 \\
\hline 3 & 45 & & & 42 & 149.5 & 498 & 498 \\
\hline 4 & 55 & & & 56 & 167.5 & 604.9 & 605 \\
\hline 5 & 65 & & & 70 & 156 & 714.9 & 715 \\
\hline 6 & 75 & & & 84 & 178 & 824.9 & 825 \\
\hline 7 & 85 & & & 98 & 228 & 934.9 & 935 \\
\hline
\end{tabular}

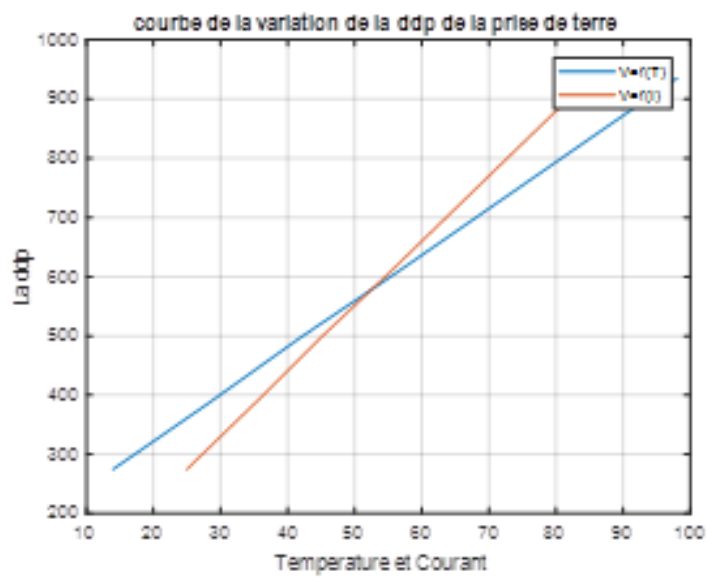

Figure 5: Evolution of the pitch voltage around the ground
Socket of the Lingwala HV substation as a function of the lightning current injected into the ground and the temperature

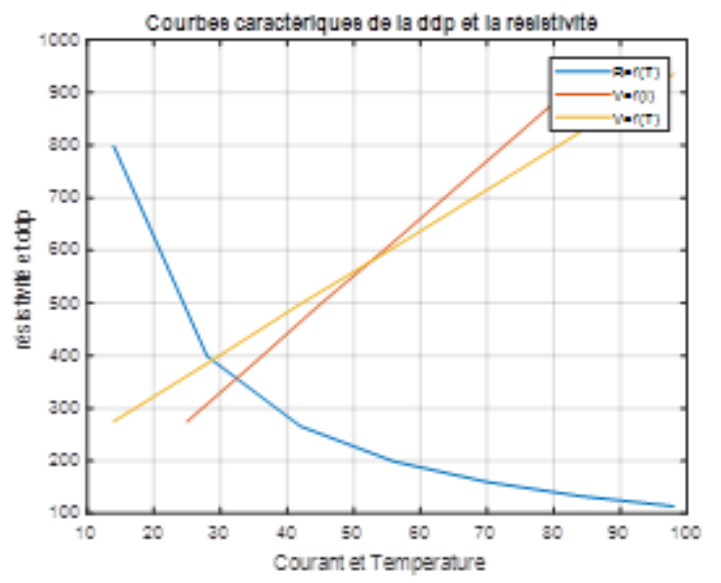

Figure 6: Evolution of ground resistivity, pitch voltage as a function of lightning current and temperature

\section{Discussion Of The Results}

The first case, which fits with a constant amplitude of the lightning current, an average of $60 \mathrm{kA}$, is close to the reality of the phenomenon studied because the resistivity of the soil is related to its nature and decreases when the temperature of the ground increases as shown in the figure above.

In the chosen temperature range, the resistivity values do not deviate too much from the average values recorded in Table 1 for clay-sand soil.

The difference in potential or the tension of steps around the grounding of the HT substation, the reference site of our investigations, is not related to thermal phenomena; it is always constant by Table 3 . This reality remains the same for other types of soil.

Regarding the second case, it is possible that during the discharge of lightning the current conveyed by the tracer varies in its path but at the point of impact on the ground, the recorded value always remains constant; which is not the case with the second possibility which consists of a variable lightning current.

Resistivity undergoes fluctuations for increasing temperature, which does not fit with the reality of soil thermal phenomena. 


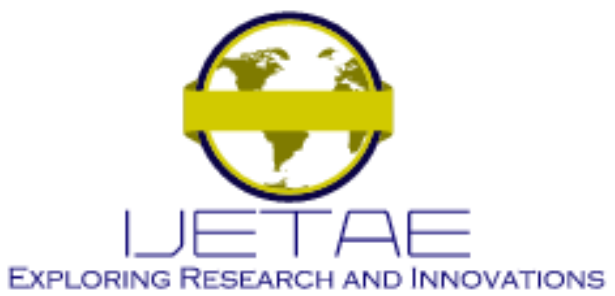

International Journal of Emerging Technology and Advanced Engineering

Website: www.ijetae.com (E-ISSN 2250-2459, Scopus Indexed, ISO 9001:2008 Certified Journal, Volume 12, Issue 01, January 2022)

\section{CONCLUSION}

Careful and careful observation of all of the above leads us to finally stress that, the lightning current is injected into the ground, the heat released is partly stored in the soil and causes an increase in the temperature of the medium that can be ionized by the joule effect while the unstored heat diffuses in the soil to places where the temperature is lower.

According to the dynamic model of underfloor heating used, only the phenomenon of diffusion was taken into account in our investigations on thermal impacts thanks to the knowledge of the thermal conductivity of the soil of the city of Kinshasa whose nature is either sandy, clayey or clay-sandy.

Thanks to the samples of the resistance of the ground intake measured at the Lingwala/Kinshasa substation, we showed that the resistivity of the soil varies exponentially with the temperature of the soil and its nature during the flow of lightning current to the ground; which is different from the approximations given by Mathieson's expression where the resistivity of metals varies linearly with temperature

\section{REFERENCES}

[1] Jinliang He, Rong Zeng, Bo Zhang. "Methodology and Technology for Power System Grounding", Wiley, 2012

[2] Kigotsi Kasereka. "Analysis of the lightning activity of thunderstorm systems in the basin Du Congo », doctoral thesis at the University of Toulouse, 2018.

[3] A. Pasi Bengi Masata "General Electricity", ed Alliance CCC, 2005.

[4] G. Semaan Georges «Evaluation of the effect of the sea and the counterweight on the voltage profile of an earthing system for an HV electrical power transmission line in a resistive soil », doctoral thesis, Higher Technological School, University of Quebec, 2001.

[5] T. Wildi , «Electrotechnique », les presses universitaires de Laval, 3éme éd, 1999

[6] Sunde, «Conduction effets in transmission system, New York, Dover

[7] Tagg.GF, «Earth Résistances, George New Ness LTD, London 1964. Pubic, 1968.

[8] Tagg.GF, «Earth Résistances » George New Ness LTD, 1964.

[9] HTTP //: www.geo.fr/environnement, 2011 